\title{
IMPLEMENTAÇÃO E AVALIAÇÃO DE UM BIODIGESTOR DE PRODUÇÃO DESCONTÍNUA
}

\section{IMPLEMENTATION AND EVALUATION OF A BATCH DIGESTER}

\author{
Ely Dias Duarte Neto, Leonardo Henrique Alvarenga, Lilian de Melo Costa, Paulo Henrique \\ Nascimento, Rafael Zanini Silveira, Leonardo Henrique de Melo Leite \\ Centro Universitário de Belo Horizonte - UniBH, Belo Horizonte, MG \\ ely.neto@materdei.com.br; lh.alvarenga@uol.com.br; \\ lilianmello16@yahoo.com.br; paulonascimento88@hotmail.com; \\ rafaelzanini_15eyahoo.com.br; leonardo.leite@prof.unibh.br
}

\begin{abstract}
Resumo - $O$ desenvolvimento do ser humano está intrinsecamente ligado aos tipos de energia que teve acesso. $O$ domínio sobre o fogo foi o primeiro grande passo para a humanidade. O uso do GAS NATURAL tem início no século XX nos EUA, mas com as exportações da Rússia, que possui a maior reserva do planeta, o gás natural tomou espaço do carvão nas termoelétricas. Hoje o gás natural se tornou o energético mais utilizado em termoelétricas e seu consumo vem crescendo em todo o mundo. Este artigo descreve um experimento de implantação de um biodigestor mostrando a equivalência entre a produção de biogás, a quantidade de material utilizado e a prática que procura prover um pequeno produtor de uma fonte energética. A biomassa, após passar pelo biodigestor e ter produzido o biogás, também tem como produto o biofertilizante, para a fertilização dos solos.
\end{abstract}

Palavras-Chave - Biomassa. Biodigestor. Biogás. Energia Alternativa.

Abstract - The human development is intrinsically linked to the types of energy that had access. The control of the fire was the first big step for mankind. The use of GAS NATURAL begins in the twentieth century in America, but with exports to Russia with the largest reserves on the planet, natural gas took place in the coal fired power. Today natural gas has become the world more energy used in power plants and is the fastest growing energy use in the world. This article describes an experimental implementation of a digester showing the equivalence between the production of biogas and the amount of material used and the practice that seeks to provide a small producer of an energy source. The biomass, after passing through the digester and producing biogas, also produces biofertilizer for fertilization of soils.

Keywords - Biomass. Biodigestor. Biogas. Alternative Energy.

\section{INTRODUÇÃO}

Todos os organismos biológicos que podem ser aproveitados como fontes de energia, são chamados de Biomassa: a cana-de-açúcar, o eucalipto, a beterraba, o biogás (produzido pela biodegradação anaeróbica existente no lixo e dejetos orgânicos), lenha e carvão vegetal, óleos vegetais (amendoim, soja, dendê), etc.

A biomassa é formada pela combinação de dióxido de carbono da atmosfera e água na fotossíntese, que produz os hidratos de carbono; a energia solar é armazenada nas ligações químicas dos componentes estruturais da biomassa.

Se a biomassa for queimada de modo eficiente, há produção de dióxido de carbono e água. Portanto, o processo é cíclico e pode-se dizer que a biomassa é um recurso renovável.

A biomassa é uma das fontes para produção de energia com maior potencial de crescimento nos próximos anos. Tanto no mercado internacional quanto no interno, ela é considerada uma das principais alternativas para a diversificação da matriz energética e a consequente redução da dependência dos combustíveis fósseis. Dela é possível obter energia elétrica e biocombustíveis, como o biodiesel e o etanol, cujo consumo é crescente em substituição aos derivados de petróleo como o óleo diesel e a gasolina. 
A Biomassa tem sido usada de forma crescente no mundo como insumo energético; muito mais para usos finais como energia térmica, mas, já de forma importante, como geradora de energia elétrica e, de forma também crescente, como origem de combustíveis líquidos (etanol e o biodiesel). Em 1996 estimava-se em 33 - 35 EJ (cerca de $11 \%$ do consumo mundial) a produção de energia da biomassa, em diversas formas (CTENERG, 2001).

\section{OS BIODIGESTORES}

\section{II.1 A MATÉRIA PRIMA (BIOMASSA)}

Qualquer matéria orgânica que possa ser transformada em energia mecânica, térmica ou elétrica é classificada como biomassa. De acordo com a sua origem, a biomassa pode ser: florestal (madeira, principalmente), agrícola (soja, arroz e cana-de-açúcar, entre outras) e rejeitos urbanos e industriais (sólidos ou líquidos, como o lixo). Os derivados obtidos dependem da matéria-prima utilizada, cujo potencial energético varia de tipo para tipo e da tecnologia de processamento para obtenção dos energéticos.

Nas regiões menos desenvolvidas, a biomassa mais utilizada é a de origem florestal. Além disso, os processos para a obtenção de energia se caracterizam pela baixa eficiência - ou necessidade de grande volume de matéria-prima para produção de pequenas quantidades. Uma exceção a essa regra é a utilização da biomassa florestal em processos de co-geração industrial. Do processamento da madeira durante a extração da celulose é possível, por exemplo, extrair a lixívia negra (ou licor negro) usado como combustível em usinas de co-geração da própria indústria de celulose.

Já a produção em larga escala da energia elétrica e dos biocombustíveis está relacionada à biomassa agrícola e à utilização de tecnologias eficientes. A pré-condição para sua produção é a existência de uma agroindústria forte e com grandes plantações, sejam elas de soja, arroz, milho ou cana-de-açúcar.

A biomassa é obtida pelo processamento dos resíduos dessas culturas. Assim, do milho é possível utilizar, como matéria-prima para energéticos, sabugo, colmo, folha e palha. Da soja e arroz, os resíduos que permanecem no campo, tratados como palha. Na cana-de-açúcar, o bagaço, a palha e o vinhoto.

A geração de energia a partir da biomassa animal encontrava-se, em 2008, em fase quase experimental, com poucas usinas de pequeno porte em operação no mundo. Por isso, em estatísticas e estudos, era tratada pela designação genérica de "Outras Fontes". Já para a biomassa de origem vegetal, o quadro era radicalmente diferente, em função da diversidade e da aceitação de seus derivados pelos consumidores (ANEEL, 2010).

\section{II.2 TIPOS DE BIODIGESTORES}

Os biodigestores podem ser encontrados em diversos modelos (indiano, paquistanês, chinês, tailandês, filipino, etc.) cada qual com suas vantagens e desvantagens e características próprias de operação. Entretanto, existem dois tipos básicos de biodigestores classificados de acordo com a frequência de operação: os biodigestores em "batelada" e os biodigestores "contínuos" (FARIA, 2008).

Chama-se de biodigestores "em batelada" àqueles que operam de forma descontínua, $o$ processo de biodigestão se dá por cargas que são inseridas no compartimento de fermentação. Esse processo é utilizado quando, por algum motivo, não é possível a alimentação do biodigestor com matéria orgânica diariamente, ou, quando o consumo de biogás é baixo, não exigindo uma produção diária do biogás.

Nesses biodigestores a matéria orgânica é inserida toda de uma só vez e então ele é fechado hermeticamente (de forma a não permitir a entrada de oxigênio) até que ocorra o processo de digestão anaeróbia. O biodigestor será aberto novamente só quando a produção de biogás cair, indicando que a matéria orgânica já foi decomposta e que pode ser feita a retirada da matéria restante, o biofertilizante, para, caso seja necessário, ser inserida nova carga de matéria orgânica.

Já os biodigestores de operação "contínua" operam com cargas diárias de matéria orgânica que se movimenta por meio de carga hidráulica dentro do biodigestor devendo a matéria orgânica, 
portanto, ser diluída e até mesmo triturada para evitar entupimentos e formação de crostas no interior do biodigestor.

Os modelos indiano, chinês e paquistanês são modelos de biodigestores de operação contínua e os dois primeiros são, também, os mais utilizados no Brasil devido ao baixo custo, alto rendimento e fácil manuseio.

\section{II.3 VANTAGENS E DeSVANTAGENS}

A produção de biogás representa um avanço importante no sentido da solução do problema da disponibilidade de combustível no meio rural e, por conseguinte, interessa a toda a população nele residente. A redução das necessidades de lenha poupa as matas. Representa, também, um importante meio de estímulo à agricultura, promovendo a devolução de produtos vegetais ao solo e aumentando o volume e a qualidade de adubo orgânico. Os excrementos fermentados aumentam o rendimento agrícola.

O biogás, substituindo o gás de petróleo no meio rural, elimina também os custos do transporte de bujão de gás dos estoques do litoral ao interior.

O uso do biogás na cozinha é higiênico, não desprende fumaça e não deixa resíduos nas panelas. As donas de casa ficam livres de pesadas tarefas domésticas de mobilizar carvão e lenha para a cozinha.

O desenvolvimento de um programa de biogás também representa um recurso eficiente para tratar os excrementos e melhorar a higiene e o padrão sanitário do meio rural.

O lançamento de dejetos humanos e animais num digestor de biogás soluciona o problemas de dar fins aos ovos dos esquistossomos e ancilóstomos, bem como de bactérias, bacilos desintéricos e paratíficos e de outros parasitas. O número de ovos de parasitas encontrados no efluente é de 99\%, após a fermentação. (AMBIENTE BRASIL, 2010).

Entre as principais vantagens destacam-se:

- Período de construção reduzido (1,5 a 2 anos).

- Investimentos em moeda nacional.

- Combustível de baixo custo quando comparado a combustíveis fósseis.

- Localização próxima ao ponto de consumo com redução nos custos de transmissão de energia.

- Projetos são elegíveis ao Mecanismo de desenvolvimento Limpo estabelecido pelo Protocolo de Quioto.

Entre as principais desvantagens destacamse:

- Menor poder calorífico.

- Maior possibilidade de geração de material particulado para a atmosfera. Isto significa maior custo de investimento para a caldeira e os equipamentos para remoção de material particulado.

- Dificuldades no estoque e armazenamento.

\section{II.4 CONDIÇÕES ANAERÓBICAS}

As bactérias metanogênicas apresentam uma sensibilidade enorme às variações do ambiente e a diversos outros fatores. Por isso é aconselhável a observação de alguns fatores que irão oferecer uma melhor qualidade de biogás e o aumento da segurança na sua produção; que são os seguintes:

1. Inexistência de $\mathrm{Ar}$

O Oxigênio $(\mathrm{O} 2)$ do ar é letal para as bactérias anaeróbicas. Se houver oxigênio no ambiente, as bactérias anaeróbicas paralisam seu metabolismo e deixam de se desenvolver. As bactérias aeróbicas (que utilizam o oxigênio em seu metabolismo) produzem dióxido de carbono (CO2) como produto final de sua respiração. As archaeas metanogênicas produzem metano $(\mathrm{CH} 4)$. Enquanto que o metano é um gás rico em energia química e, portanto, pode ser usado como combustível, o dióxido de carbono já está totalmente oxidado e não pode ser usado como combustível. Se o biodigestor não estiver hermeticamente vedado contra a entrada de ar, a produção de biogás não ocorre porque as bactérias anaeróbicas morrem e as aeróbicas sobrevivem. O biogás produzido será então rico em $\mathrm{CO} 2$ e não em metano. Assim, o biodigestor deve assegurar uma completa hermeticidade que cause uma completa falta de oxigênio em seu interior, isto é, a completa anaerobiose do ambiente necessária para $o$ metabolismo das bactérias anaeróbicas. 
2. Temperatura adequada

A temperatura no interior do biodigestor é um parâmetro importante para a produção de biogás. As archaeas que produzem metano são muito sensíveis a alterações de temperatura. Alterações de temperatura que excedam 45 graus Celsius ou vão abaixo de 15 graus Celsius paralisam a produção de biogás. Assim, outro papel do biodigestor é o de assegurar certa estabilidade de temperatura para as bactérias.

\section{Nutrientes}

Os principais nutrientes dos microorganismos são o carbono, nitrogênio e sais minerais. Fontes ricas de nitrogênio são os dejetos de animais (inclusive seres humanos). Fontes ricas de carbono são os restos de culturas vegetais. Os sais minerais presentes nos dejetos animais e resíduos vegetais são suficientes para a nutrição mineral das bactérias. No entanto, se não houver um adequado equilíbrio de compostos de carbono (que fornecem a energia) e de compostos nitrogenados (que fornecem o nitrogênio) não ocorrerá uma eficiente produção de biogás.

\section{Teor de água}

O material a ser fermentado deve possuir em torno de 90 a 95\% de umidade em relação ao peso, valores muito acima ou muito abaixo destes limites podem prejudicar a produção de biogás. O teor da água varia de acordo com as matérias-primas destinadas à fermentação. $\mathrm{O}$ esterco de bovino (que possui em média $84 \%$ de umidade) precisa ser diluído em $100 \%$ de seu peso em água, já o de suínos (com 19\% de umidade) precisa de 130\% de seu peso em água, o de ovinos e caprinos, em $320 \%$.

\section{II.5 BIODIGESTÃO}

A biodigestão ou fermentação anaeróbica consiste num método de reciclagem de materiais orgânicos para a formação do Biogás e Biofertilizante. Podemos dividi-la em três partes distintas, sendo elas: fase da Hidrólise, fase Ácida e a fase Metanogênica; contudo, a produção do biogás só ocorre na última fase, e a obtenção do biofertilizante surge somente no final de todo o processo, que varia de 40 a 55 dias.

\section{Fase da Hidrólise}

Nesta fase da biodigestão as bactérias liberam no meio as chamadas enzimas extracelulares, cuja função é realizar a chamada hidrólise das partículas, que nada mais é do que a transformação, ou quebra, das moléculas maiores (polissacarídeos) em ácidos orgânicos (ácido láctico e ácido butílico), alcoóis, $\mathrm{H} 2$ e CO2; estas mesmas bactérias realizam ainda a fermentação de proteínas e lipídeos.

\section{Fase Ácida}

Nesta etapa as bactérias que produzem os ácidos transformam as moléculas de proteínas, gorduras e carboidratos em moléculas de ácidos orgânicos, etanol, amônia, hidrogênio, dióxido de carbono, dentre outros compostos.

\section{Fase Metanogênica}

$\mathrm{Na}$ terceira e última fase do processo as bactérias denominadas metanogênicas atuam sobre $o$ hidrogênio e o dióxido de carbono e os transforma em metano (biogás). Esta é a parte mais demorada do processo, pois com o decorrer das reações químicas ocorre a formação de microbolhas de metano e dióxido de carbono em torno da bactéria metanogênica, isolando-a de um contato direto com a mistura. Por este motivo, é aconselhada uma agitação no biodigestor, para poder estourar essas microbolhas.

Deve ser levado em conta o tempo de transição destes processos, que se dá geralmente de 15 dias até a Fase Metanogênica, e consequentemente o início da produção do biogás, entretanto, recomenda-se que as duas primeiras cargas sejam descartadas (os dois primeiros dias), pelo motivo de haver uma grande concentração de dióxido do carbono. O tempo que o biodigestor pode levar produzindo biogás varia entre 25 a 40 dias, sendo que o biofertilizante só poderá ser retirado no final do processo, ou seja, após 40 a 55 dias (UNIFEB, 2009).

\section{II.6 BIOGÁS}

O biogás é uma mistura gasosa feita principalmente, de dióxido de carbono $(\mathrm{CO} 2)$ e de metano (CH4). Tem uma baixa densidade e é mais leve que o ar, apresentando desta forma menores riscos de explosões, já que a sua acumulação se torna mais difícil que a dos demais gases. $\mathrm{O}$ 
biogás, além do $\mathrm{CO} 2$ e $\mathrm{CH} 4$, contém uma mistura de vários elementos gasosos, conforme listado na Tabela 1.

Tabela 1 - Biogás - Elementos gasosos (MARTIN, 2004).

\begin{tabular}{|l|c|}
\hline \multicolumn{1}{|c|}{ Elemento } & Porcentagem \\
\hline Metano $\left(\mathrm{CH}_{4}\right)$ & 50 a 75 \\
\hline Dióxido de Carbono $\left(\mathrm{CO}_{2}\right)$ & 25 a 40 \\
\hline Hidrogênio $\left(\mathrm{H}_{2}\right)$ & 1 a 3 \\
\hline Azoto $\left(\mathrm{N}_{2}\right)$ & 0.5 a 2.5 \\
\hline Oxigênio $\left(\mathrm{O}_{2}\right)$ & 0.1 a 1 \\
\hline Sulfureto de Hidrogênio $\left(\mathrm{H}_{2} \mathrm{~S}\right)$ & 0.1 a 0.5 \\
\hline Amoníaco $\left(\mathrm{NH}_{3}\right)$ & 0.1 a 0.5 \\
\hline Monóxido de Carbono $(\mathrm{CO})$ & 0 a 0.1 \\
\hline Água $\left(\mathrm{H}_{2} \mathrm{O}\right)$ & Variável \\
\hline
\end{tabular}

O combustível do biogás é o gás metano, conhecido também como gás dos pântanos. O poder calorífico do biogás é proporcional à porcentagem deste gás (metano) na mistura. O metano é um gás combustível, produzido basicamente por fontes antropogênicas e naturais. Ele é encontrado naturalmente em depósitos geológicos, que são conhecidos como campos de gás natural, geleiras, em pântanos e em lugares que possuem baixa concentração de oxigênio.

O biogás, além de ser um combustível de fácil acesso e de custos baixos, não polui, e em certas escalas obtém-se um melhor resultado com ele do que com combustíveis fósseis. Tem-se que:

$1 \mathrm{~m}^{3}$ de biogás $=5500 \mathrm{kcal}$, é equivalente a:

- $0,7 \mathrm{~m}^{3}$ de metano

- $1,5 \mathrm{~m}^{3}$ de gás de cidade

- 0,81 de gasolina

- 1,31 de álcool

- $2 \mathrm{~kg}$ de carboneto de cálcio

- $\quad 0,71$ de gasóleo

- $7 \mathrm{kw} / \mathrm{h}$ de eletricidade

- $2,7 \mathrm{~kg}$ de madeira

- $\quad 1,4 \mathrm{~kg}$ de carvão de madeira

- $0,2 \mathrm{~m}^{3}$ de butano

- $0,25 \mathrm{~m}^{3}$ de propano

- $1 \mathrm{~m}^{3}$ de biogás é equivalente a um botijão de $13 \mathrm{Kg}$ de GLS (gás liquefeito do petróleo ou gás de cozinha)
- $\quad 1 \mathrm{~m}^{3}=1000$ litros (os valores são variáveis, pois a quantidade de kcal do biogás depende da pureza do material utilizado, e a sua quantidade de calor fica entre 5000 kcal até $6600 \mathrm{kcal})$.

Na Tabela 2 são mostrados os valores médios de produção de biogás por quilo de material fermentado. Foram incluídos nesta tabela, somente os materiais de maior disponibilidade no meio rural.

Tabela 2 - Capacidade de geração de biogás (CETEC, 1981).

\begin{tabular}{|l|c|}
\hline \multicolumn{1}{|c|}{ Material } & $\begin{array}{c}\text { Produção de } \\
\text { Gás (litros/ kg) }\end{array}$ \\
\hline Esterco de bovinos & 36 \\
\hline Esterco de suinos & 52 \\
\hline Esterco de equinos & 100 \\
\hline Esterco de aves & 240 \\
\hline Resíduos vegetais & 25 \\
\hline
\end{tabular}

\section{IMPLEMENTAÇÃo DO PROJETO PILOTO}

\section{III.1 OBJETIVOS}

O Brasil dispõe de condições climáticas favoráveis para explorar a imensa energia derivada dos dejetos animais e restos de cultura e dispensar o gás de bujão e o combustível líquido (querosene, gasolina, óleo diesel) para o homem urbano (ou rural) aliviando, com isso, o país de uma significativa parcela de importação de derivados do petróleo. $\mathrm{O}$ alcance de um programa de substituição de fontes de energia por biogás pode ser avaliado tomando-se a produção dos 7,2 milhões de biodigestores instalados na China até dezembro 1979, que tem um valor energético equivalente a cinco "Itaipus" ou 48 milhões de toneladas de carvão mineral.

Esse projeto foi desenvolvido com o objetivo de analisar a viabilidade técnica, econômica, financeira e ambiental de um sistema produtivo utilizando como matéria prima o esterco de bovinos. Um projeto piloto experimental de biodigestor produzido em escala reduzida foi concebido e implantado. 


\section{III.2 MetodologiA}

Para a implantação desse projeto foram feitas pesquisas e levantamentos a respeito da matriz energética do Brasil.

Uma vez definidas as fontes alternativas de energia mais viáveis foi realizado um estudo aprofundado sobre a produção de energia a partir da biomassa. Em seguida, foram realizados estudos sobre o funcionamento de biodigestores, e sobre suas aplicações. Após levantamentos decidiu-se sobre o tipo de biodigestor que seria mais viável para a implantação e estudos. Basicamente, o projeto propôs uma avaliação dos reais benefícios trazidos por uma produção de energia "limpa".

A estratégia utilizada para a avaliação energética do biogás de esterco de bovinos foi a implementação de um biodigestor para produção do biogás. $\mathrm{O}$ esquema do sistema de produção proposto é apresentado na Figura 1.

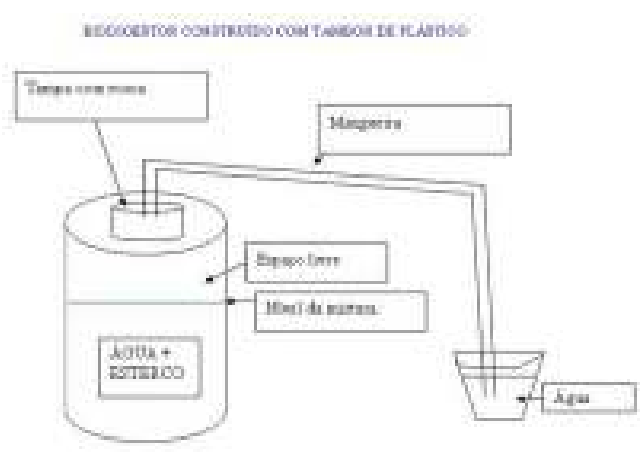

Figura 1 - Biodigestor construído com tambor de plástico (PROINFA, 2010).

\section{III.3 IMPLANTAÇÃO}

Materiais

Tambor plástico de 20 litros.

Esterco fresco de bovinos ( $8 \mathrm{Kg})$.

Água destilada (8 litros).

Massa plástica para vedação.

Pedaço de mangueira para gás $(1,5 \mathrm{~m})$.

Medidor volumétrico para gás.

Método de construção

A construção do biodigestor foi realizada seguindo os seguintes passos:

1) Faz-se um furo na tampa do tambor, encaixe o pedaço de mangueira e vede de modo que não tenha vazamentos.
2) Abasteça o tambor com esterco fresco diluído em água na proporção de 1 parte de água para 1 parte de esterco, deixando uma folga no volume do tambor de 10 a $20 \%$.

3) Coloque a tampa no tambor, de modo que a extremidade da mangueira ou cano não fique mergulhada na mistura de esterco e água.

Para medir a produção de biogás, a exemplo de Ortiz-Canavate et al. (1981), foi utilizado um medidor volumétrico para gás. Esse medidor é de fabricação de Liceu Indústria e apresenta as seguintes especificações técnicas:

- Marca: LAO

- Modelo: MG-6

- Carga nominal: 6 m3.h-1

- Vazão mínima: 0,06 m3.h-1

- Pressão máxima de trabalho: $1000 \mathrm{mmca}$

- Aplicação: medida volumétrica de metano/biogás

\section{RESULTADOS}

O biogás produzido diariamente pelo sistema é o produto principal a ser avaliado pela pesquisa, tanto qualitativa, como quantitativamente. $\mathrm{O}$ volume de biogás foi registrado no medidor e anotado em intervalos de 1 dia.

Tabela 3: Anotações das medições.

\begin{tabular}{|c|c|}
\hline Dias & Valores $\mathbf{( m}^{\mathbf{3}} \mathbf{)}$ \\
\hline $13 / 11 / 2010$ & 0,041 \\
\hline $14 / 11 / 2010$ & 0,042 \\
\hline $15 / 11 / 2010$ & 0,043 \\
\hline $16 / 11 / 2010$ & 0,044 \\
\hline $17 / 11 / 2010$ & 0,046 \\
\hline $18 / 11 / 2010$ & 0,048 \\
\hline $19 / 11 / 2010$ & 0,052 \\
\hline $20 / 11 / 2010$ & 0,062 \\
\hline $21 / 11 / 2010$ & 0,068 \\
\hline $22 / 11 / 2010$ & 0,073 \\
\hline $23 / 11 / 2010$ & 0,078 \\
\hline $24 / 11 / 2010$ & 0.082 \\
\hline
\end{tabular}

$\mathrm{Na}$ Tabela 3 observa-se a evolução da produção de biogás durante 12 dias. A partir dos valores nela registrados foi construído o Gráfico 1, que mostra a variação da produção de biogás em função do tempo. É possível notar que com o 
decorrer dos dias a produção de biogás vai acumulando ate atingir o seu valor máximo, a partir daí a produção diminui tendendo a zero, pois o biodigestor implementado é de produção descontínua.

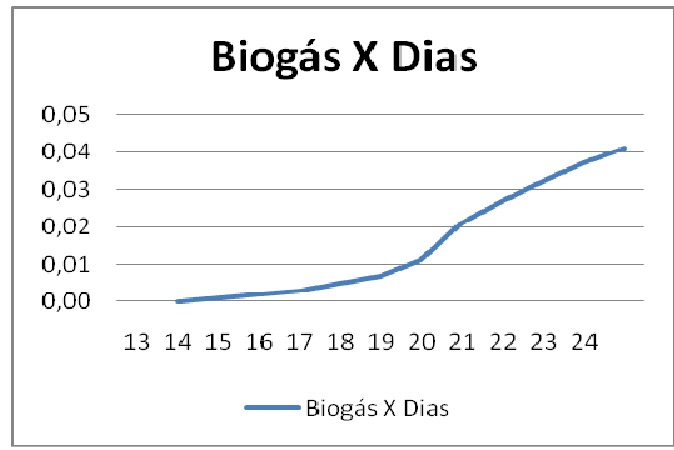

Gráfico 1: Produção de Biogás em doze dias.

No Gráfico 2 a curva representa a variação na produção de biogás em função da temperatura. Quando a temperatura está em torno de $24{ }^{\circ} \mathrm{C}$ ou acima desse valor, há uma maior produção de biogás, devido à mudança de inclinação da curva que representa o volume do biogás. Quando a temperatura cai abaixo dos $24^{\circ} \mathrm{C}$, nota-se a desaceleração na produção de biogás, observada pela mudança de inclinação da curva.

Seguindo como referência a Tabela 2 e considerando o tempo de produção média de 45 dias, em 11 dias esperava-se a produção de $0,089 \mathrm{~m}^{3}$ de biogás. O valor encontrado no medidor foi de $0,082 \mathrm{~m}^{3}$. Como o medidor iniciou o processo em $0,41 \mathrm{~m}^{3}$, tem-se que a produção real de biogás neste experimento foi de $0,041 \mathrm{~m}^{3}$. Ou seja, $46 \%$ da produção esperada.

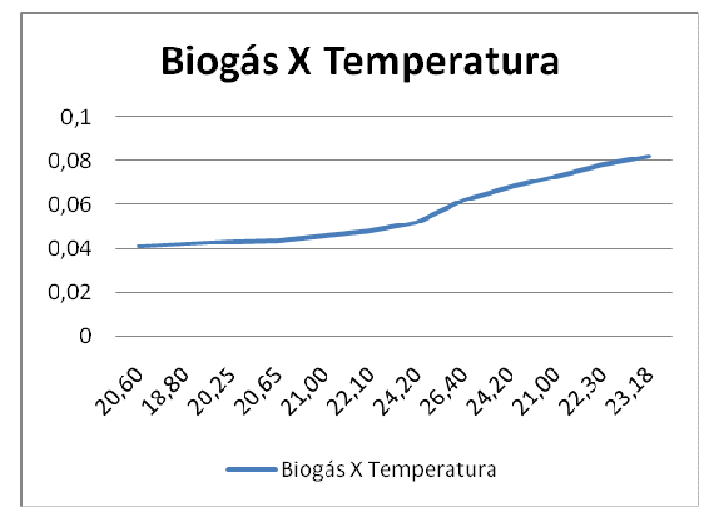

Gráfico 2: Biogás em relação a temperatura ambiente.

Conforme observado no Gráfico 2 a baixa temperatura ambiente influenciou diretamente na produção do biogás. Segundo Sganzerla (1983) a temperatura é o fator que tem maior relevância na produção de biogás e o intervalo de temperatura ideal está entre $28^{\circ} \mathrm{C}$ e $35^{\circ} \mathrm{C}$.

\section{CONCLUSÕES}

Os resultados desse projeto piloto mostraram a viabilidade da utilização de biodigestores para a geração de biogás como fonte alternativa de energia, porém deve-se observar rigorosamente os procedimentos para construção do mesmo, verificando sempre as condições anaeróbicas para não haver perda durante a produção.

Conclui-se que a utilização de biodigestores é boa alternativa no meio rural, devido à abundância de matéria prima. $\mathrm{O}$ biodigestor é fonte de energia para as caldeiras, geradores, fogões e outros. Com isso a utilização de biodigestores se torna viável considerando seu baixo investimento e o rápido retorno, melhorando assim a relação custo $\mathrm{x}$ beneficio.

Conclui-se também que apesar de ser fonte de energia proveniente da natureza, não causando a mesma quantidade de poluição que os combustíveis fósseis e outras fontes de energia convencionais, a utilização de biodigestores deve ser feita de maneira consciente evitando a liberação de metano para a atmosfera.

\section{REFERÊNCIAS}

ANEEL - Agência Nacional de Energia Elétrica. Atlas de Energia Elétrica do Brasil, Fontes renováveis Parte II - Biomassa. Disponível em: $<$ http://www.aneel.gov.br/arquivos/PDF/atlas_ par2_cap4.pdf $>$. Acesso em: abril 2010.

Ambiente Brasil - Ambiente Energia Biodigestores. Disponível em: http://ambientes.ambientebrasil.com.br/energia/arti gos energia/biodigestores.html. Acesso em: set. 2010 .

Centro Universitário da Fundação Educacional de Barretos- UNIFEB. Relatório do Projeto Integrado I. Setembro 2009. Disponível em: http://www.ebah.com.br/biodigestor-doca27526.html Acesso em: ago. 2010. 
CETEC - Fundação Centro Tecnológico de Minas Gerais. Manual para Construção e Operação de Biodigestores. 1981

CTENERG - Secretaria Técnica do Fundo Setorial de Energia. Centro de Gestão e Estudos Estratégicos: Ciência, Tecnologia e Inovação. Geração de Energia Elétrica a partir de Biomassa no Brasil: situação atual, oportunidades e desenvolvimento. Junho 2001. Disponível em: < http://www.cgee.org.br/arquivos/estudo003_02.pdf >. Acesso em: abril 2010.

FARIA, Caroline. Tipos de Biodigestores, 2008. Disponível em:

http://www.infoescola.com/energia/tipos-debiodigestores/. Acesso em: set. 2010.

MARTIN, Osvaldo Stella. Aproveitamento da Biomassa para a Geração de Energia Elétrica. $1^{\circ}$ Seminário sobre a Utilização de Energias
Renováveis para Eletrificação Rural do Norte e Nordeste do Brasil, Centro Nacional de Referência em Biomassa - CENBIO, 2004

ORTIZ-CAÑAVATE, J.; HILLS, D.J.; CHANCELLOR, W.J. Diesel engine modification to operate on biogas. Transaction ASAE, Amsterdam, p.808-813, 1981.

PROINFA - Programa de Incentivo às Fontes Alternativas de Energia Elétrica, 2010. Disponível em: $<$ http://www.mme.gov.br/programas/proinfa. Acesso em: Abril 2010.

SGANZERLA, E. Biodigestor: uma solução. Porto alegre: Agropecuário, 1983, 88p.

SOUZA, Rodrigo G.; SILVA, Fabio M.; BASTOS, Adriano C. Bastos. Desempenho de um conjunto motogerador adaptado a biogás, Ciênc. agrotec., Lavras, v. 34, n. 1, p. 190-195, jan./fev., 2010 